UDK 528.344

\title{
APPLICATION OF GNSS TECHNOLOGY IN SURFACE MINING
}

\section{Dana VRUBLOVÁ ${ }^{1}$, Roman KAPICA ${ }^{2}$, Beáta GIBESOVÁ ${ }^{3}$, Jaroslav MUDRUŇKA ${ }^{4}$, Adam STRUŚ ${ }^{5}$}

\author{
1,3,4 The Institute of Combined Studies in Most, VSB-Technical University of Ostrava, \\ Dělnická 21, Most, Czech Republic \\ 2,5Institute of Geodesy and Mining Surveying, Faculty of Mining and Geology, \\ VSB - Technical University of Ostrava, 17. listopadu 15, CZ-708 33 Ostrava, Czech Republic \\ E-mails: ${ }^{1}$ dana.vrublova@vsb.cz; ${ }^{2}$ roman.kapica@vsb.cz (corresponding author); \\ ${ }^{3}$ beata.gibesova@vsb.cz; ${ }^{4}$ jaroslav.mudrunka; ${ }^{5}$ adam.strus.st@vsb.cz
}

Received 02 July 2016; accepted 30 November 2016

\begin{abstract}
VŠB - Technical University of Ostrava, institute of geodesy and mine surveying has been cooperating with Severočeské doly j.s.c. (SD) in important research project since 2007. The main goal is improve control system for opencast mining. Two bucket wheel excavators (K800/103 and KU300/27) were equipped with measurement hardware at the Libouš Lignite Mine (North Bohemia brown coal basin). The position of the bucket wheel centre is computed by means of GNSS data, inclinometer and incremental measurements. Data is transferred to a base. All the values measured are saved in this database. The surface layout of the mine as well as positions of underground geological layers are updated on a regular basis in the digital model of the mine. The main aim of the research is verifying the system in connection to digital model for short time prognosis of qualitative parameters of coal (Ad, Sd, Qr, Wr and MS), continuous automatic computation of mined materials ( $\mathrm{m}^{3}$, tons) and continuous checking of creation of the movement surface/plane of the excavator and mining goals. Mine surveyors have a lead role in the working team. The paper describes possibilities of using the GNSS for mine surveying and for production planning.
\end{abstract}

Keywords: analysis, bucket wheel excavator, digital model, GNSS, inclinometer, incremental measurements.

\section{Introduction}

The fact that the satellite system provides data independently of weather conditions, round the clock and anywhere in the world is a major advantage of the system. During the last two decades the satellite technology has been undergoing fast developments worldwide, which has resulted in the use of GNSS technology in many fields. In the surface mining industry the GNSS has proven to be useful mainly at resolving usual surveying tasks. The option is now investigated of utilisation the GNSS technology also for facilitation of the mining process.

\section{Use of the GNSS for determination of excavator bucket wheel position}

It is obvious that if the $3 \mathrm{D}$ position of excavation elements of mining machinery and associated mining mechanisms can be determined relatively accurately, multiple task can be successfully resolved in terms of control of this hardware. As far as brown coal surface mines are concerned, the following topics are of prime interest (Rucký et al. 2004):

- Facilitation of the process of control of excavator operation (e.g. prognoses of qualitative parameters of coal being mined).

- Calculations of volumes of mined materials in nearly real time.

- Very accurate control of creation of the movement plane of the excavator and immediate control of mining targets.

- Control and checking of associated mining mechanisms (e.g. dozers).

In 2006 Severočeské doly j.s.c. launched a research project titled "GNSS-Aided Determination of the Position of the Bucked Wheel of the K800/103/N1 Excavator" (Fig. 1). A project was developed, in which all the components of the system were designed, including their positions, as well as systems of data transfers and data evaluation. 
The system consisted of three basic elements (Talácko 2007):

- Measurement segment (GNSS, inertial sensors, control unit).

- Communication segment (radio or GPRS communication for reception and transmission of data).

- User segment (evaluation software).

On bucket wheel excavator K800/103 (Fig. 2) the measurement segment originally (2006) consisted of 2 DGPS devices Trimble DSM 232 (Dot 1, Dot 2), 2 inclinometers (Dot 3, Dot 4) and one incremental rotation speed sensor (Dot 5). Corrections for DGPS were transferred from the reference station to the excavator employing a radio-modem. A control unit controls the operation of the entire system. The position of the centre of the bucket wheel axis (Dot 6) is computed from $\mathrm{X}, \mathrm{Y}, \mathrm{Z}$ coordinates acquired from the GNSS devices and on the basis of sensors' data (inclinations, rotation speeds) on a 5-second basis. Using radio-modems, the data is transmitted to the headquarters building of the Surveying and Geology Department, where it is saved. Then the data is processed by evaluation software (KVAS Prognosis Models). The system has been operated since December 2006.

\section{The research programme}

The data transferred is saved in database file ${ }^{*}$.DB. All the values measured are saved in this database. On a five-second basis the database should be updated with a series of newly measured values. The first tools have already been developed in the "KVAS - Prognosis Model" programme for visualisation of the excavator and utilisation of the results of computation of the position of the centre of the bucket wheel axis (Jiránková 2012).

The section of digital operational map in (Fig. 3) shows the position of schematized K800/103 excavator. On the left hand side, the vertical geological profile is shown in simplified terms. The position of the bucket wheel in relation to the profile in the relevant site can be seen. The individual types of coal are colour-discerned on the basis of qualitative parameters. Mining plan for excavator is also shown (red lines) as well as boreholes. Another view is on (Fig. 4). The current status and the history of qualitative parameters of the coal (Elevation of bucket wheel - 1, Heating Value $\mathrm{Qr}-2$ and sulphur content Sd - 3), as derived from the model, can be seen in the left part of the figure.

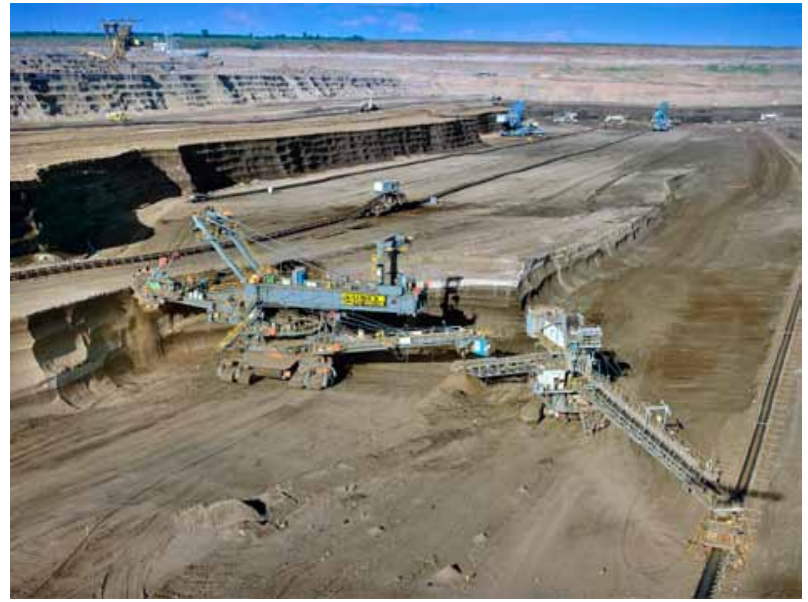

Fig. 1. Surface mining - Libouš mine

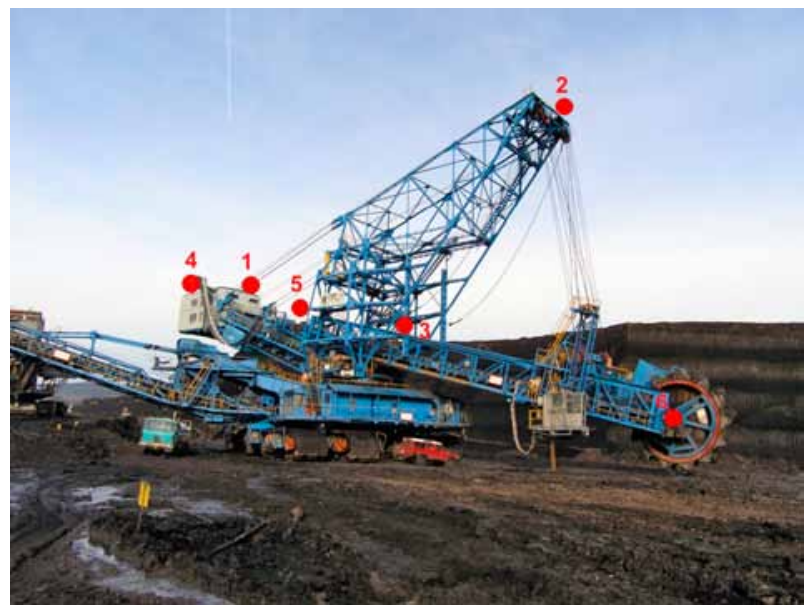

Fig. 2. K800/103 excavator

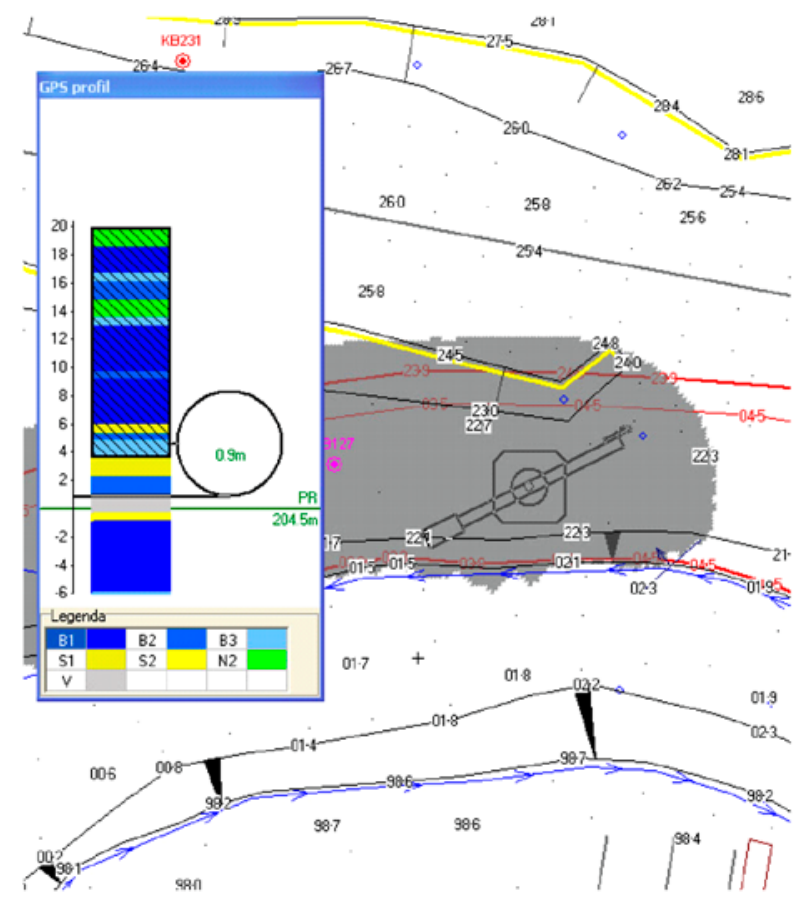

Fig. 3. The position of the bucket wheel excavator in real time (map and profile) 
The measured data also serves for detailed analysis of the entire process. The analysis is developed by the Institute of Geodesy and Mine Surveying of the Technical University - VŠB Ostrava. The following is carried out in particular:

- Analysis of data transfer (number of measurements received).

- Analysis of accuracy of individual meters (Analysis of gross errors; Analysis of the mean errors of individual measurements and identification of the critical point; Comparison of computed mean errors with values identified by the manufacturers of all the used meters).

- Analysis of the accuracy of the calculation of the bucket wheel axis centre (mean error propagation).

- Analysis of data during operation of the excavator.

The basic equations for determination of $3 \mathrm{D}$ (XK, $\mathrm{YK}$ and $\mathrm{ZK}$ ) bucket wheel axis position were derived

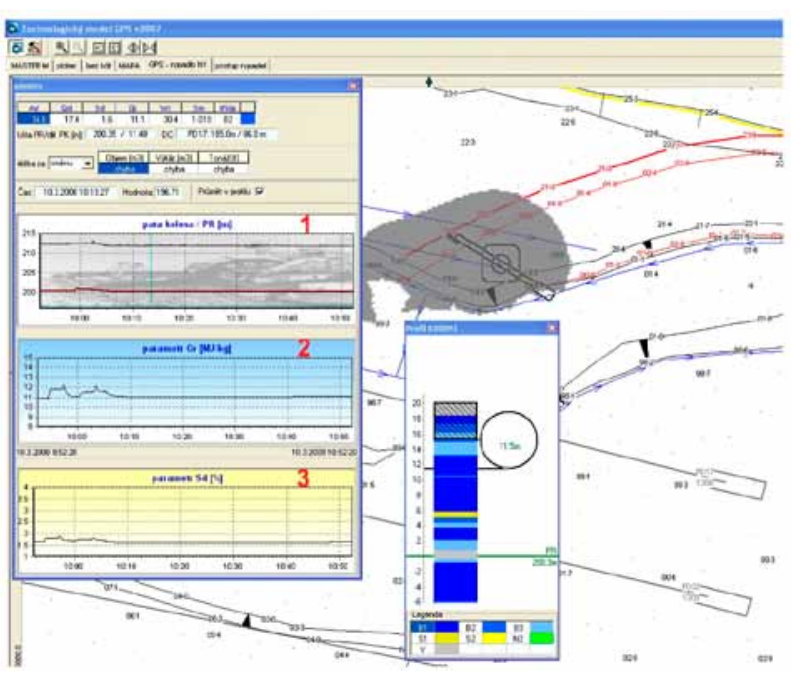

Fig. 4. Elevation of bucket wheel and qualitative parameters of the coal (left part of the figure)

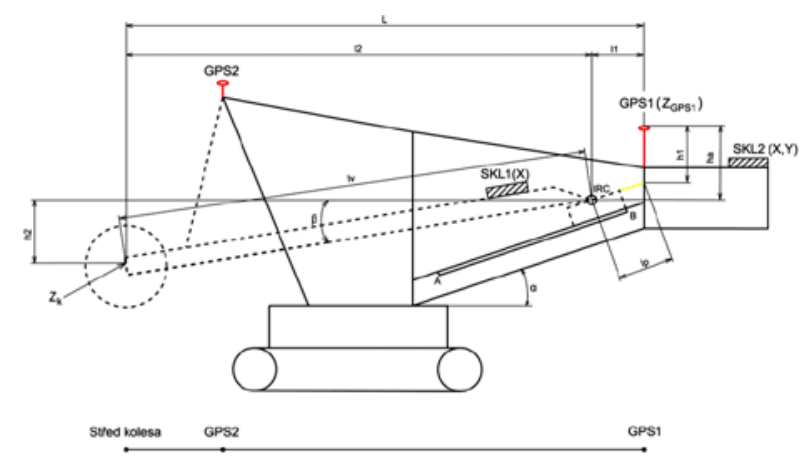

Fig. 5. Positions of GNSS and inertial sensors at the K800/103 excavator from geometry of excavator and positions of GNSS and inertial sensors at the K800/103/N1 (Fig. 5) excavator (1), (2), (3):

$$
\begin{gathered}
Y_{K}=Y_{G P S 1}+\sin \left(\operatorname{arctg} \frac{Y_{G P S 2}-Y_{G P S 1}}{X_{G P S 2}-X_{G P S 1}}\right) \times \\
{\left[\left(7.557+I R C \frac{12.03}{40423}\right) \times\right.} \\
\left.\cos \left(19.648-S K L 2_{-} X\right)+(35.966 \times \cos S K L 1)\right] ; \\
X_{K}=X_{G P S 1}+\cos \left(\operatorname{arctg} \frac{Y_{G P S 2}-Y_{G P S 1}}{X_{G P S 2}-X_{G P S 1}}\right) \times \\
{\left[\left(7.557+I R C \frac{12.03}{40423}\right) \times\right.} \\
\left.\cos \left(19.648-S K L 2 \_X\right)+(35.966 \times \cos S K L 1)\right] ;
\end{gathered}
$$

$$
\begin{aligned}
& Z_{K}=Z_{G P S 1}-\left\{\left[1,77+\sin \left(19.648-S K L 2_{-} X\right) \times\right.\right. \\
& \left.\left.\left(7.557+I R C \frac{12.03}{40423}\right)\right]+35.966 \times \sin S K L 1\right\} .
\end{aligned}
$$

Accuracy of calculation 3D bucket wheel axis position was derived using of mean error propagation method:

$$
\begin{aligned}
& \sqrt{\left(\frac{\partial Y_{K}}{\partial Y_{G P S 1}} \cdot m_{Y_{G P S 1}}\right)^{2}+\left(\frac{\partial Y_{K}}{\partial Y_{G P S 2}} \cdot m_{Y_{G P S 2}}\right)^{2}+} \\
& m_{Y_{K}}= \pm\left\{\begin{array}{l}
\left(\frac{\partial Y_{K}}{\partial X_{G P S 1}} \cdot m_{X_{G P S 1}}\right)^{2}+\left(\frac{\partial Y_{K}}{\partial X_{G P S 2}} \cdot m_{X_{G P S 2}}\right)^{2}+ \\
\left(\frac{\partial Y_{K}}{\partial I R C} \cdot m_{I R C}\right)^{2}+\left(\frac{\partial Y_{K}}{\partial S K L 2_{-} X} \cdot m_{S K L 2 \_X}\right)^{2}+
\end{array}\right. \\
& \left(\frac{\partial Y_{K}}{\partial S K L 1} \cdot m_{S K L 1}\right)^{2} \\
& \left(\frac{\partial X_{K}}{\partial Y_{G P S 1}} \cdot m_{Y_{G P S 1}}\right)^{2}+\left(\frac{\partial X_{K}}{\partial Y_{G P S 2}} \cdot m_{Y_{G P S 2}}\right)^{2}+ \\
& \left(\frac{\partial X_{K}}{\partial X_{G P S 1}} \cdot m_{X_{G P S 1}}\right)^{2}+\left(\frac{\partial X_{K}}{\partial X_{G P S 2}} \cdot m_{X_{G P S 2}}\right)^{2}+ \\
& \left(\frac{\partial X_{K}}{\partial I R C} \cdot m_{I R C}\right)^{2}+\left(\frac{\partial X_{K}}{\partial S K L 2_{-} X} \cdot m_{S K L 2_{-} X}\right)^{2}+ \\
& \left(\frac{\partial X_{K}}{\partial S K L 1} \cdot m_{S K L 1}\right)^{2}
\end{aligned}
$$




$$
m_{Z_{K}}= \pm \sqrt{\left(\frac{\partial Z_{K}}{\partial Z_{G P S 1}} \cdot m_{Z_{G P S 1}}\right)^{2}+\left(\frac{\partial Z_{K}}{\partial I R C} \cdot m_{I R C}\right)^{2}+}
$$

The equations (4-6) for mean errors $m_{X_{K}}, m_{Y_{K}}$ and $m_{Z_{K}}$ of $X_{K}, Y_{K}$ and $Z_{K}$ calculation we got using partial derivation. The final equations are quite extensive therefore we do not bring them in the article. We appointed values of mean errors individual measurement instruments to Equations (4), (5), (6) (final version) and have obtained mean errors $m_{X_{K}}, m_{Y_{K}}$ and $m_{Z_{K}}$ influenced by accuracy of individual measurement instruments.

\section{Partial conclusions from the research project (2007)}

The accuracy of determination of the position and elevation of the centre of the wheel axis depends also on the reliability of transfer of corrections from the reference station to the excavator as, unless the corrections are transferred from the reference station to the excavator, GNSS receivers switch automatically from the DGPS mode to the "navigation" mode - with considerably compromised accuracy. The first results of data analyses showed that it would be necessary to ensure better quality transfer of corrections from the base to the excavator and vice versa - the success rate was about $70 \%$. This, consequently, had a negative impact on the accuracy of the GNSS measurements.

The first results already suggest that for the purpose of routine application, the RTK regime will have to be used and the GNSS receivers will have to be upgraded, particularly due to the need to increase the accuracy 3D position determinations. Using DGPS technology we achieved average accuracy of determination of the position and elevation of the centre of the wheel axis:

$$
\begin{aligned}
& m_{X_{K}}= \pm 0.164 \mathrm{~m}= \pm 0.164 \mathrm{~m} ; \\
& m_{Y_{K}}= \pm 0.143 \mathrm{~m}= \pm 0.143 \mathrm{~m} ; \\
& m_{Z_{K}}= \pm 0.265 \mathrm{~m}= \pm 0.265 \mathrm{~m} .
\end{aligned}
$$

\section{The results of development in 2009}

On the results of our analysis, SD Company has realized two important changes. Radio communication for reception and transmission of data was displaced by GPRS system. 2 DGPS devices Trimble DSM 232 were changed by 2 RTK Leica MNS1230 GG. The Leica MNS1200 GNSS is specifically designed for construction and mining machine operation at toughest conditions.

The results of accuracy analysis are better now and for main future purpose - prognosis of qualitative parameters of coal to be mined in near future (short term prognoses) - are satisfying. Data transfer success rate is better than $99 \%$ and average accuracy (RMS) of determination of the $3 \mathrm{D}$ position of the centre of the wheel axis:

$$
\begin{aligned}
& m_{X_{K}}= \pm 0.025 \mathrm{~m} ; \\
& m_{Y_{K}}= \pm 0.012 \mathrm{~m} ; \\
& m_{Z_{K}}= \pm 0.041 \mathrm{~m} .
\end{aligned}
$$

\section{Analysis of internal and real accuracy of the system for Determination of Excavator Bucket Wheel Position for the period 2011-2015}

During this time, the position of two points on a bucket excavators was determined by using GNSS receivers (GNSS Trimble SPS 851). The inclination of the entire excavators and boom, by inclinometer (Sitall Electronic). Extension boom with incremental encoder (LARM Inc.) (Křivda 2013). In Tables 1 and 2 there are accuracies of measuring instruments (standard errors). The accuracy of the devices were analyzed except the period of mining. Wheel position has not changed. We used a large data set (5-second measurement intervals). For example on 1st July 2011 there were 17271 measurements. For evaluation was chosen period from 11:57:49 to 3:03:09 p.m., which means 2225 measurements (Fig. 6) (Sládková et al. 2011).

Table 1. Accuracy GNSS apparatus featured manufacturers

\begin{tabular}{|l|c|c|}
\hline GNSS aparature & horizontal accuracy & vertical accuracy \\
\hline $\begin{array}{l}\text { Trimble SPS } 851 \\
\text { (RTK) }\end{array}$ & $\pm 0.01 \mathrm{~m}+1 \mathrm{ppm}$ & $\pm 0.02 \mathrm{~m}+1 \mathrm{ppm}$ \\
\hline
\end{tabular}

Table 2. Accuracy inclinometer featured by producers

\begin{tabular}{|c|c|c|}
\hline Inclinometer & \multicolumn{2}{|c|}{ Accuracy (in range) } \\
\hline Sitall STS-015- & $\pm 0.1^{\circ}$ & $\pm 0.2^{\circ}$ \\
$180-2-\mathrm{RS} 232$ & ${\text { (inclination to } \pm 60^{\circ}}^{\circ}$ & (inclination $\pm 80^{\circ}$ ) \\
\hline
\end{tabular}

On large files measurements there were verified that the accuracy of the incremental rotary encoder (IRC) is several orders of magnitude higher than precision of other measuring instruments. For purposes of verifying the accuracy of the system as a whole are precision values IRC ignored and the values deemed as 


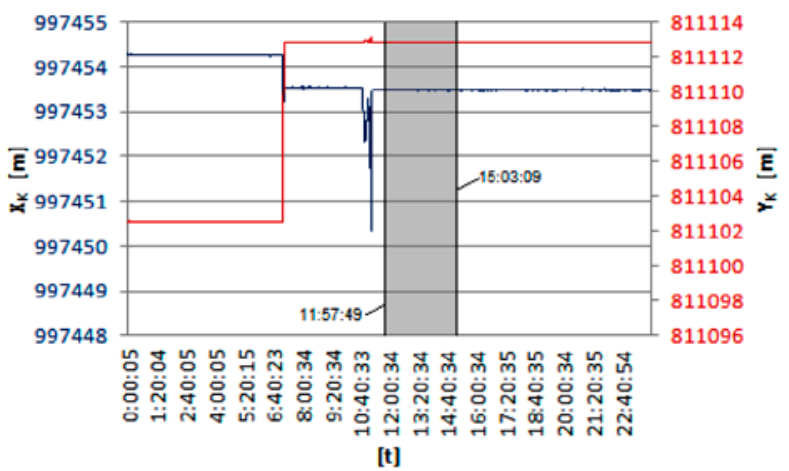

Fig. 6. Positions of GNSS and inertial sensors at the K800/103 excavator

flawless (many times shown on large sets of measurements).

Measurements whose deviation from the mean value exceeded three times the median errors were excluded from tested datasets. From the data of 1. 7.2011 were a four measurements of the number 2225 . The values of precision measuring instruments correspond to the values declared by the producers (Table 3 ).

Table 3. An average achieved accuracy of GNSS devices

\begin{tabular}{|c|c|c|}
\hline GNSS device & $\begin{array}{c}\text { Horizontal } \\
\text { accuracy }\end{array}$ & Vertical accuracy \\
\hline $\begin{array}{c}\text { Trimble SPS } 851 \\
\text { (RTK) }\end{array}$ & $0.008 \mathrm{~m}$ & $0.010 \mathrm{~m}$ \\
\hline
\end{tabular}

An average achieved accuracy of inclinometer Sitall-015-180-2 STS-232 is $\pm 0.0046^{\circ}$. There were calculated standard error of the wheel center coordinates of each affected precision surveying and measuring instruments (Table 4) (Vrublová et al. 2012).

Table 4. Results of calculation errors secondary of the center coordinates wheel axis

\begin{tabular}{|l|c|c|c|}
\hline The mean error & $m_{X_{K}}$ & $m_{Y_{K}}$ & $m_{Z_{K}}$ \\
\hline Dimension & \multicolumn{3}{|c|}{$[\mathrm{m}]$} \\
\hline Average & 0.008 & 0.007 & 0.010 \\
\hline $\begin{array}{l}\text { The resulting } \\
\text { values }\end{array}$ & \multicolumn{2}{|c|}{$m_{x y}=0.011$} & $m_{z}=0.010$ \\
\hline
\end{tabular}

Compared with the previous period, there is a noticeable qualitative shift in determining the accuracy of the wheel centre. Achieved accuracy is a kind of intrinsic accuracy of the measuring instruments. The actual accuracy of the system can be verified by geodetic methods and is significantly lower. Still it is suitable for applications such as digital terrain model

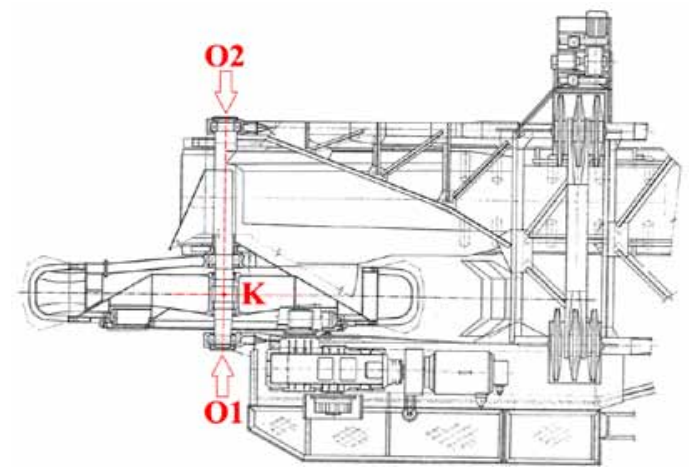

Fig. 7. Detail of wheel boom with Excavator Bucket Wheel. Centre of wheel (point $\mathrm{K}$ )

updates, prediction of qualitative parameters of coal, applications for elimination of risks and volume calculations of extracted masses. Direct measurement of the center of the axis of the wheel has not been possible, because it is a point that is inside the wheel and it is technically impossible to focus. There was chosen procedure, when there were measured the attitude and altitude oriented centers of both ends of the axis of the wheel, which are available for targeting. These are points $\mathrm{O} 1$ and $\mathrm{O} 2$, which are targeted to the Figure 7 by arrow.

The last measurement was on Nástup Tušimice mine since 13. 5. 2015 to 2. 6. 2015 and on Bílina mine since 5. 5. 2015 to 21 5. 2015. There were measured standpoints for measurements of points $\mathrm{O} 1$ and $\mathrm{O} 2$ by using GNSS with the same transformation key (same reference station) as uses GNSS receivers, which are components of excavator. From the standpoint there were measured points $\mathrm{O} 1$ and $\mathrm{O} 2$ by electronic tachymetres height and attitude and the center position against the wheel (usually not centreline) measured points $\mathrm{O} 1$ and $\mathrm{O} 2$ there were calculated coordinates of the center axis of the wheel XK, YK and ZK (point $\mathrm{K})$. For simplicity, the coordinates were acquired by control geodetic measurement, regarded as correct. Simultaneously, a database system for monitoring wheel in real time deducted coordinates of the center axis of the wheel XK, YK and ZK calculated from measurements of measuring instruments on an excavator at a time when the inspection took place by measurement.

Comparison of coordinates obtained from the system for the center axis of the wheel and the geodetic measurement are in Tables 5 and 6. Deviations of Oxy express the deviation in position and $\mathrm{Oz}$ is the deviation in height.are in Tables 5 and 6. Deviations of Oxy express the deviation in position and $\mathrm{Oz}$ is the deviation in height. 
Table 5. Results of control at Nástup Tušimice mine

\begin{tabular}{|c|c|c|c|c|}
\hline \multirow{2}{*}{ Excavator } & \multirow{2}{*}{ Day } & Time & $O_{x y}$ & $O_{z}$ \\
\cline { 3 - 5 } & & {$[\mathrm{h}]$} & \multicolumn{2}{|c|}{$[\mathrm{m}]$} \\
\hline K800/103 & 13.5 .2015 & $8: 25$ & 0.37 & 0.01 \\
\hline K800/104 & 14.5 .2015 & $8: 35$ & 0.38 & 0.06 \\
\hline KU300/64 & 14.5 .2015 & $10: 05$ & 0.31 & -0.02 \\
\hline KU300/76 & 14.5 .2015 & $9: 20$ & 0.08 & -0.08 \\
\hline KU300/88 & 14.5 .2015 & $9: 00$ & 0.22 & -0.06 \\
\hline KU300/89 & 14.5 .2015 & $9: 40$ & 0.47 & 0.15 \\
\hline SchRs1550/109 & 21.5 .2015 & $10: 05$ & 0.20 & 0.27 \\
\hline KU800/106 & 21.5 .2015 & $8: 50$ & 0.66 & -0.06 \\
\hline SchRs1320/110 & 2.6 .2015 & $10: 31$ & 0.25 & -0.05 \\
\hline
\end{tabular}

Table 6. Results of the control measurements at Bílina mine

\begin{tabular}{|c|c|c|c|c|}
\hline \multirow{2}{*}{ Excavator } & \multirow{2}{*}{ Day } & Time & $O_{x y}$ & $O_{z}$ \\
\cline { 3 - 5 } & & {$[\mathrm{h}]$} & \multicolumn{2}{|c|}{$[\mathrm{m}]$} \\
\hline KU800/98 & 5.5 .2015 & $11: 00$ & 0.37 & 0.06 \\
\hline K2000/101 & 5.5 .2015 & $11: 55$ & 0.68 & 0.01 \\
\hline KU800/99 & 7.5 .2015 & $8: 55$ & 0.34 & -0.05 \\
\hline KK1300/111 & 7.5 .2015 & $9: 45$ & 0.36 & -0.07 \\
\hline KU302/102 & 11.5 .2015 & $9: 05$ & 0.19 & -0.24 \\
\hline KU300/70 & 11.5 .2015 & $9: 50$ & 0.20 & -0.19 \\
\hline KU300/83 & 11.5 .2015 & $10: 25$ & 0.37 & 0.27 \\
\hline KU300/68 & 13.5 .2015 & $8: 35$ & 0.71 & -0.15 \\
\hline KU800/105 & 13.5 .2015 & $9: 18$ & 0.73 & -0.14 \\
\hline KU300/91 & 21.5 .2015 & $9: 12$ & 0.37 & 0.11 \\
\hline KU300/71 & 21.5 .2015 & $9: 25$ & 0.48 & -0.10 \\
\hline
\end{tabular}

\section{The main goals}

After the research programme is completed, a complex system can come into being of measurement of positions of mining mechanisms, which could be beneficial in multiple areas:

Mining of coal, striping and combined haulage levels:

- Visualisation of the positions of excavators and their movements and elevations in real time at earmarked computers connected to the network and provided with relevant software.

- Information on the position of the wheel in relationship to the stratum profile or stripping level.

- Saving of mining procedures and their retroactive retrieval in both graphic and numerical forms (checking and analytical purposes).
- Control of creation of movement surface/plane in real time and its immediate checks.

- Computation of qualitative parameters of coal in real time with all excavators and simulation of the functions of the qualitative parameter meters.

- Development of prognosis of qualitative parameters of coal to be mined in near future (short term prognoses).

- Computation of volumes of mined materials in real time (the volumes of mined materials will be known with almost "surveying" accuracy immediately after the relevant period - day/ month).

- Measurement of extension of the wheel boom.

Facilitation of the Operative Control of Mining:

- In a modified form, the applications can also by used in notebooks and PDA. The data can hence be available anywhere in the field.

Mine planning:

- Automatic and continuous updates of the condition of haulage levels in the mining model.

- Checking of adherence to technical regimes, including mine planning maps or long term mining goals (position and elevation parameters of advances).

- Determination of the initial conditions for preparation of next month's advance on the basis of actual advance in the ongoing month. Continuous calculation and detailing of the limits of start and end of advance in the next month (period).

\section{Conclusions}

The process of mining of industrial minerals in rather complicated geological conditions (variable morphology and qualitative parameters - both vertically and horizontally, occurrence of idle underground mines etc.) cannot be presently fully automated, as is nowadays commonplace in. e.g. electrical engineering, in industry of manufacture of simple mechanical engineering products or in the food industry. Nevertheless, the developments in information technologies as well as in other technologies enable to expedite the feedback within the line of "planning - implementation-check". Information on where an excavator operates and what is being mined can be acquired (with some degree of inaccuracy) immediately. It is critical now if such mechanisms can be created that can exploit this data and influence the production process. In the meantime 
we are at the beginning of resolving the task, to which multiple disciplines will have to contribute. Through resolving the issue of accurate and reliable determination of the 3D position of the operating machineries and associated mechanisms in mines, the mining engineers, surveyors, geologists, reclamation engineers and managerial staff will acquire a tool for better control and ensuing checks of production processes during open cast mining of industrial minerals.

\section{Acknowledgements}

This article was written in connection with project Institute of clean technologies for mining and utilization of raw materials for energy use - Sustainability program. Identification code: LO1406. Project is supported by the National Programme for Sustainability I (2013-2020) financed by the state budget of the Czech Republic.

\section{References}

Jiránková, E. 2012. Utilisation of surface subsidence measurements in assessing failures of rigid strata overlying extracted coal seams, International Journal of Rock Mechanics and Mining Sciences 53: 111-119. https://doi.org/10.1016/j.ijrmms.2012.05.007

Křivda, V. 2013. Analysis of conflict situations in road traffic on roundabouts, Promet - Traffic\&Transportation: Scientific Journal on Traffic and Transportation Research 25(3): 295303. http://dx.doi.org/10.7307/ptt.v25i3.296

Rucký, P.; Blovský, J.; Vrubel, M. 2004. Některé zkušenosti s aplikací GPS v povrchovém dobývání na DNT-SD A.S. a v poránském revíru [Experience about application of GPS during open cast mining at DNT-SD PLC and in the Rhineland Coal Basin], in Uhlí-Rudy-Geologický růzkum, 2/2004.
Sládková, D.; Kapica, R.; Vrubel, M. 2011. Global navigation satellite system (GNSS) technology for automation of surface mining, International Journal of Mining, Reclamation and Environment 25(3): 284-294.

http://dx.doi.org/10.1080/17480930.2011.608879

Talácko, M. 2007. Systém pro sledování prostorové polohy kolesa rypadla K 800/N1 [System for monitoring of the spatial position of the K800/N1 excavator wheel]. Technical Report 3/2007.

Vrublová, D.; Kapica, R.; Jurman, J. 2012. Methodology devising for bucket-wheel excavator surveying by laser scanning method to determine its main geometrical parameters, Geodesy and Cartography 38(4): 157-164.

http://dx.doi.org/10.3846/20296991.2012.757438

Dana VRUBLOVÁ. Ing., PhD Asst. Prof., The Institute of Combined Studies in Most, Faculty of Mining and Geology, VSB - Technical University of Ostrava. Research interests: geodesy, cartography, mine surveying.

Roman KAPICA. Ing., PhD Asst. Prof., The Institute of Geodesy and Mining Surveying, Faculty of Mining and Geology, VSB - Technical University of Ostrava. Research interests: photogrammetry, laser scanning, close range photogrammetry, unmanned aircraft system.

Beáta GIBESOVÁ. Ing., $\mathrm{PhD}$, The Institute of Combined Studies in Most, Faculty of Mining and Geology, VSB - Technical University of Ostrava. Research interests: waste management, waste processing and disposal, biotechnologies.

Jaroslav MUDRUŇKA. Ing., The Institute of Combined Studies in Most, Faculty of Mining and Geology, VSB - Technical University of Ostrava. Research interests: dust prevention in coal mines.

Adam STRUŚ, Ing., Institute of Geodesy and Mining Surveying, Faculty of Mining and Geology, VSB - Technical University of Ostrava. Research interests: geodesy, cartography. 